\title{
Posterior L5-S1 transdiscal screws for high grade spondylolisthesis - a systematic review
}

1. Professor of Neurosurgery - Department of Neurology, Neurosurgery Division, State University of Campinas, Campinas-SP, Brasil 2. Professor - Department of Orthopaedic Surgery, Northwestern University Feinberg School of Medicine, Chicago, IL, USA

\section{SUMMARY}

OBJECTIVE: The surgical management of high-grade lumbar spondylolisthesis (HGLS) is complex and aims to achieve both a solid fusion that is able to support the high shear forces of the lumbosacral junction, as well as neural decompression. We performed a systematic literature review of the safety and efficacy of posterior transdiscal (PTD) screw fixation from L5S1 for HGLS and its variations. METHODS: A systematic literature review following the PRISMA guidelines was performed in the PubMed database of the studies describing the use of PTD screw fixation for HGLS. Clinical and radiological data were extracted and discussed. Study quality was assessed with the Oxford Centre for Evidence-Based Medicine Levels of Evidence.

RESULTS: Seven studies were included and reviewed; all of them were level IV of evidence. Two of them had large case series comparing different surgical techniques: one concluded that PTD was associated with better clinical outcomes when compared with standard screw fixation techniques and the other suggesting that the clinical and radiological outcomes of PTD were similar to those when an interbody fusion (TLIF) technique was performed, but PTD was technically less challenging. The remaining five studies included small case series and case reports. All of them reported the successful useful of PTD with or without technical variations.

CONCLUSIONS: Our review concludes, with limited level of evidence that PTD fixation is a safe and efficient technique for treating HGLS patients. It is technically less demanding than a circumferential fusion, even though proper screw insertion is more demanding than conventional pedicle screw fixation.

KEYWORDS: Spondylolisthesis. Spondylolysis. Lumbar Vertebrae/surgery. Review.

\section{INTRODUCTION}

Spondylolisthesis is a forward slip of one vertebra over the other (the word "spondylo" refers to "spine" and "listhesis" means "slippage"). According to Meyerding classification, the severity of the listhesis may be graded according to how far a vertebral body has slipped forward'. High grade lumbar spondylolisthesis (HGLS) includes those classified as grade III, IV and V (or spondyloptosis, when the vertebral body above has completely fallen of the vertebra below $)^{2-5}$.
HGLS may have many causes such as a congenital defect in the pars interarticularis (dysplastic origin), an acquired injury to the pars (isthmic), and, more rarely, may be due to degenerative lumbar disease $e^{2-5}$.

Surgical treatment is accepted for symptomatic patients (generally for those with symptoms of radiculopathy and/or low back pain) with HGLS and, according to some authors, even for some asymptomatic cases with evidence of radiological progression ${ }^{3}$. 
The management of these cases is complex and aims to achieve both a solid fusion that is able to support the high shear forces of the lumbosacral junction, as well as neural decompression. Additionally, improving or maintaining sagittal balance and normal or near normal spino-pelvic relations is also desired. These goals of solid arthrodesis, neurological decompression, and restoration of sagittal parameters are balanced by the risks of surgical treatment ${ }^{2}$.

Many techniques for surgical management of HGLS have been described. The most common include:

1) Nerve root decompression with removal of the loose lamina and the fibrocartilaginous tissue (also known as Gill procedure) ${ }^{6}$

2) In situ fusion with autologous iliac crest graft (without reduction in patients with a preserved sagittal balance), with or without decompression (laminectomy $)^{7}$,

3) Posterior instrumented fusion with pedicle screws, with or without sacral dome resection for reduction ${ }^{2}$,

4) Bohlman technique, which consists in inserting a transsacral fibular strut graft after decompression and posterior arthrodesis with iliac crest $^{8}$,

5) Posterior reduction with interbody cages and pedicle screws 5 .

6) Posterior transdiscal (PTD) S1L5 screw fixation (with or without laminectomy) and arthrodesis9.

The best technique to treat HGLS is still debated and decision-making is heavily influenced by radiological characteristics, patients' clinical symptoms and also surgeon's experience and preferences. In our practice, we have successfully treated patients with HGLS using transdiscal L5-S1 screw fixation. We performed a systematic literature review of the safety and efficacy of transdiscal screw fixation of L5S1 for HGLS and its variations.

\section{METHODS}

We performed a systematic literature review following the PRISMA (Preferred Reporting Items for Systematic Reviews and Meta-Analyses) guidelines ${ }^{10}$.

The following search entries were used in the PubMed database for search (First search), without time restriction "high grade AND spondylolisthesis AND transdiscal" (First search). Another independent search was performed using other search entries: "transvertebral AND screw" (Second search). Only articles written in English were included. Manual search of cross-references was also performed, after screening the obtained articles and their references.

Studies of the use of transdiscal L5S1 screw fixation for HGLS (Meyerding grade III, IV and V) were included, since they described in detail the surgical technique, the complications and the patients' outcome. Duplicate studies were eliminated. Studies including patients with grade I and II were also excluded.

The search was performed on May 22, 2017. Study quality was assessed with the Oxford Centre for Evidence-Based Medicine Levels of Evidence categorization ${ }^{11}$.

We extracted patient age and gender, clinical symptoms, description of the surgical approach and hardware used, complications and follow-up. Reduction was also documented, as well as clinical improvement or deterioration after the procedure.

A flow chart of our search mechanism is shown in Figure 1.

\section{RESULTS}

A total of five studies were obtained in the first search $^{12-16}$, and three additional studies ${ }^{9,12,17}$ were found in the second, including the study that proposed this technique9. One study was not considered because it included many patients with spondylolisthesis grades I and $\mathrm{II}^{16}$.

FIGURE 1 - FLOW DIAGRAM OF OUR SEARCH MECHANISM ACCORDING TO THE PRISMA GUIDELINES

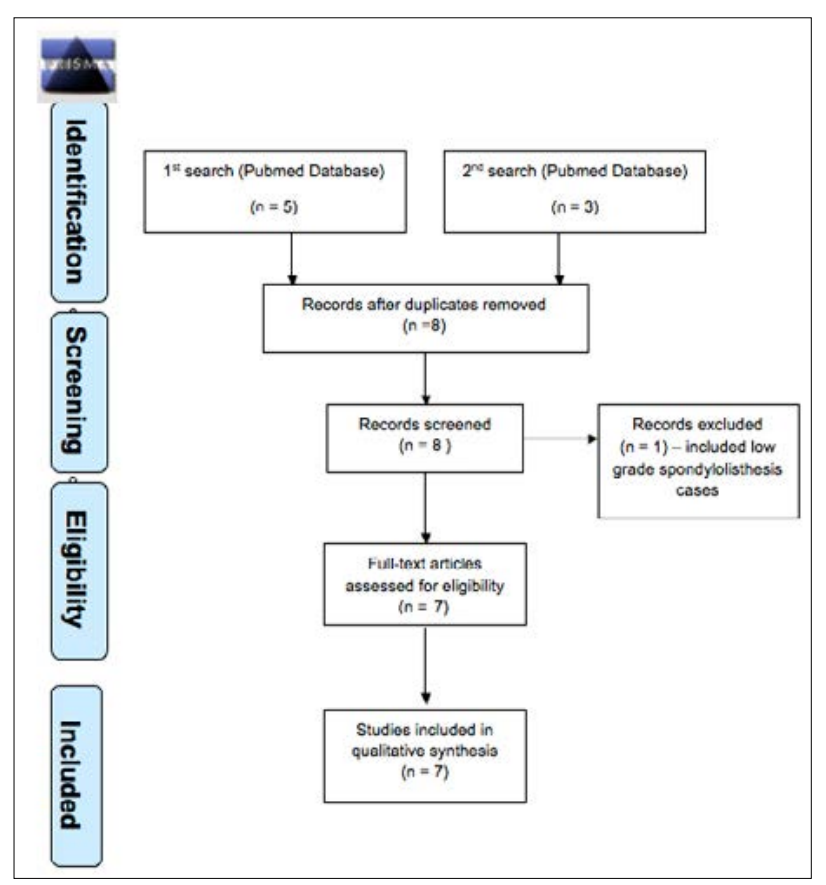


The majority of the studies were small case series, which precluded a systematic assessment of the risk of bias. All of them were level IV of evidence.

There were two large case series comparing different surgical techniques: one from Collados-Maestre et al. ${ }^{13}$ and the other from Rodriguez-Olaverri et al. ${ }^{17}$. A total of 45 cases were treated with PTD in these studies.

Collados-Maestre et al..$^{13}$ compared the outcomes of transdiscal versus conventional pedicle screw fixation for HGLS in a retrospective case-control study. Twenty-five patients had PTD fixation (mean age - 36.7 years old) and 31 had standard pedicle screw fixation (mean age -42 years old), with a mean follow-up of 2.7 years (ranging from 2 to 5.3). Preoperative data were comparable between groups. Surgery time $(p=0.598)$, blood loss $(p=0.857)$, and hospital stay $(0.126)$ were similar between groups.

PTD technique consisted in placing screws through the S1 pedicle toward the endplate of S1, crossing the disc space and the inferior endplate of L5, to finish at the L5 vertebral body. In 22 patients $(88 \%)$ the instrumented level was L4S1 and in $3(12 \%)$ the level was L5S1. Fusion without reduction was performed in 23 patients (92\%) and partial listhesis reduction (manipulating the L5 vertebral body) was performed in two patients (8\%). In the pedicle group, 23 patients $(71 \%)$ had L4-S1 fixation and 8 patients $(29 \%)$ had an L5-S1 fusion. Fusion without reduction was performed in $25(81 \%)$ patients and 6 had some partial reduction (19\%). Interbody fusion was also performed in 3 patients using L5S1 cages. Decompression was performed in both groups and posterolateral fusion was also performed using grafts from the laminectomies with additional iliac bone grafts and/or bone substitutes.

Considering the surgical technique, there were no differences in the level of instrumentation (L45 -S1 versus $L 5-S 1)-p=0.311-$ or in the reduction rate (partial versus in situ) $-\mathrm{p}=0.276$.

At the last follow-up, clinical and radiographic outcomes were significantly improved in both groups. Postoperatively, both lumbar and leg pain VAS were similar between groups, but ODI (20.2 vs. 31.6, $p=$ 0.010 ), COMI (1.6 vs. $2.8, \mathrm{p}=0.012$ ), and SF-12 physical (84.3 vs. $61.5, p=0.004)$ and mental ( 81.5 vs. 69.4 , $p=0.021)$ scores were significantly better in the transdiscal group. The neurologic complication rate was similar in both groups. There were 4 pseudoarthrosis in the pedicle group (revised using transdiscal screw technique), and none in the transdiscal group. Four patients (16\%) had poor orientation of the PTD screws with one of them presenting with a L5 radiculopathy that required the removal of the screw.

The authors concluded that PTD screws resulted in improved functional outcome compared with standard screw techniques but it is technically more demanding, due to the difficulty to place them properly. The potential advantages may be attributed to its improved fixation strength.

Rodriguez-Olaverri et al. ${ }^{17}$ compared the outcomes of patients treated for HGLS (grade III to V of Meyerding) with two different techniques: 1) unilateral transforaminal interbody fusion (TLIF) with 20 patients (Group A), and 2) transvertebral screw fixation (20 patients) (Group B). Age ranged from 19 to 48 years old (mean 33 years old) and the mean follow-up was 35 months (range, 24-48 months).

Both groups had the hip extended in order to reduce the slip angle, and horizontalize the L5 endplate. Group A patients were treated with nerve root decompression, reduction with posterior instrumentation (L4, L5, S1 and Ilium) and insertion of a TLIF. Group B patients had partial lumbosacral kyphosis reduction and received a transdiscal S1L5 screw and a L4 pedicle screw.

They reported that in Group A the median surgical time was 4.45 hours (3.45 to 5.25) in group A, with 100\% fusion, with improvement, according to the SRS scores, in postoperative pain control, self-image and function. The average slip angle improved from $38.6^{\circ}$ to $23.8^{\circ}$ but there was no significant improvement in the percentage of slippage. Complication included seven inadvertent durotomies and 3 superficial infections.

In Group B the median surgical time was 3.25 hours (2.3 to 4.25), with 95\% fusion at 6 months (19 of 20 cases), with improvement in postoperative pain control and function according to the SRS scores. The average slip angle improved from $38.2^{\circ}$ to $23^{\circ}$ but there was no significant improvement in the percentage of slip. Complications included one inadvertent durotomy, two superficial infections and in one instance pseudoarthrosis that resulted in implant failure. There was no neurological complication in any group.

The authors concluded that no significant differences in radiological and clinical outcomes were found between the two groups (both procedures appeared to be safe and effective). They also noted the difficulty in inserting a TLIF in HGLS, a potential increase in the risk of intraoperative complications. 
The remaining five studies included small case series or case reports: Abdu et al. ${ }^{9}$ with three cases (the technique was described in one of them), François et al. ${ }^{14}$ with four cases and, finally, with one case report each, Beringer et al. ${ }^{12}$, Jo et al. ${ }^{18}$ and Palejwala et al. ${ }^{15}$. A total of 10 cases were performed in those five remaining studies.

Abdu et al. ${ }^{9}$ was the first to report the use of PTD screw in three consecutive adult patients with grade III Spondylolisthesis. They named the technique "pedicular trasvertebral screw fixation”, emphasizing its safety and efficacy.

The technique is described as a posterior decompression followed by screws inserted through the pedicle of S1, transfixing the L5S1 disc into the body of L5, followed by additional two pedicles of L4 and posterior fusion using autologous iliac crest graft.

The three patients were 41, 63 and 55 years old by the time they were operated. Two of them had a previous surgery (Gill procedure with Harrington rods with pseudoarthrosis in one and a Gill procedure with an in situ fusion of L4 to the sacrum). All of them had a solid fusion (documented with a bone bridge through the extension of the fusion and the absence of motion on dynamic plain radiographs). Two patients had only mild symptoms in the last follow-up and one was no longer symptomatic. No patient required further surgical exploration.

François et al. ${ }^{14}$ reported the results of four cases of patients with HGLS treated with transdiscal screws. Patients had L4 pedicle screw fixations, without fixation of the pedicle of L5. Then, posterior transdiscal screws were placed $(7 \mathrm{~mm}$ in diameter from S1 to L5) with rod connections and posterolateral fusion with autologous bone graft from the iliac crest. Notably, no laminectomy was reported.

Patients were respectively 30, 33, 39 and 74 years old. All had low back pain and three also had radicular symptoms. All had fusion after one year without direct complications related to the procedure and had some reduction off the slip angle postoperatively (mean slip angle preoperatively was $23.5^{\circ}$ versus $17.5^{\circ}$ postoperatively). The authors also reported that all four patients did have bone formation in the disc space of L5S1 in spite of no interbody fusion nor discectomy being performed.

Beringer et al. ${ }^{12}$ reported a technical note of a modified PTD fixation. They reported an illustrative case of a 34-year-old man who had back pain with radicular pain and a grade III spondylolisthesis. An anterior ret- roperitoneal approach was performed, inserting an in situ L5-S1 transvertebral cage (a K wire was advanced obliquely from L5 anterosuperior region through L5 body, crossing the disc space of L5S1 and entering S1 vertebral body) and a L45 ALIF, followed by posterior transdiscal S1L5 screws and L4 pedicle screws connected with a rod and posterior decompression with posterolateral fusion from L4 to S1. The patient was still doing well after several months.

Jo et al. ${ }^{18}$ reported a case of a lumbosacral spondyloptosis (grade V) in a 70-year-old osteoporotic woman with low back pain, radicular symptoms (2/5 motor strength for anterior tibialis and extensor hallucis longus muscle groups) and also intermittent urinary incontinence. They performed a laminectomy of the loose arch of L5, removed the scar tissue around the pars of L5, and decompressed the L5 nerve roots. After that, bilateral L2, 3, 4 and iliac screw fixation was performed, the L5S1 disc space was accessed, and an interbody spreader was used to lift the body of L5 superior and posteriorly. Then, an S1 pedicle was guided through the L5S1 disc and to the body of L5. Rods were then connected to the system and autologous bone grafts were used laterally. After seven days, a second procedure was performed, with ALIF at L34 and 45 and, using a $\mathrm{K}$ wire for guidance, a $6 \mathrm{~mm}$ diameter screw was passed from the body of L5 and directed to the body of S1. The authors reported that after 10 months of follow-up, the patient had minimal back pain and no more urinary retention, with recovery of muscle strength (grade $4 / 5$ ).

Palejwala et al. ${ }^{15}$ reported the results of a case report of an adolescent patient (12 years-old) with an L5S1 grade IV spondylolisthesis treated with bilateral transsacral transdiscal screw fixation and additional L4 pedicle screws, with decompression of the neural elements with graft obtained from the local bone decompression. The patient had progressive back pain despite conservative management. He was neurologically intact. After 14 months, the patient had significant improvement of his symptoms with a solid bone fusion. They concluded that this technique was safe and effective to treat HGLS in adolescents.

An illustrative case (Figure 2) of transdiscal screw fixation is presented.

\section{DISCUSSION}

High-grade spondylolisthesis is a rare condition that represents the minority of the cases of spondy- 


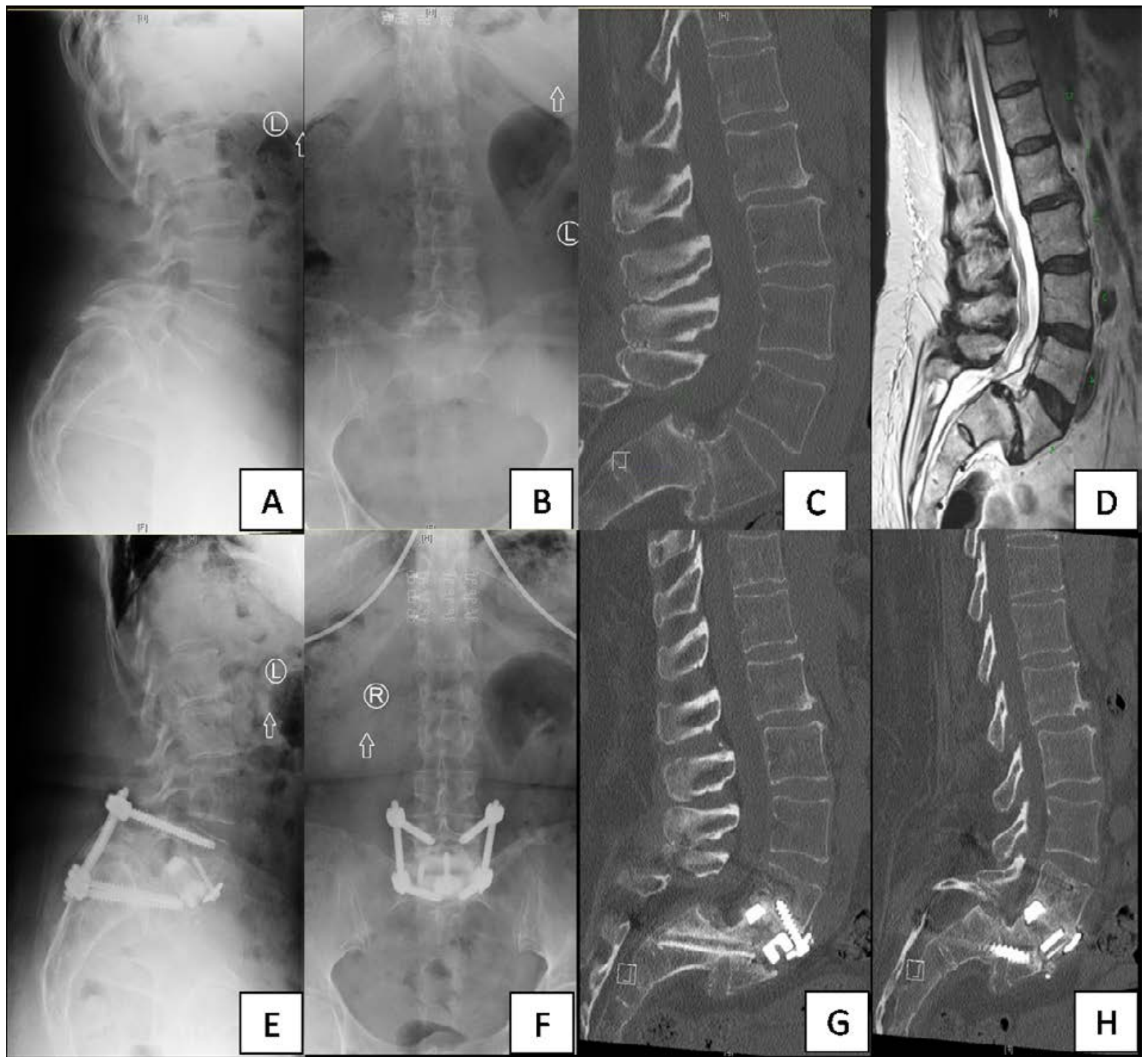

FIGURE 2 - A 65-year-old woman presented with severe episodes of acute and mechanical low back pain and leg pain. A- Lateral lumbar spine with a lytic L5 and a grade III L5S1 spondylolisthesis. B- Antero-posterior simple plain radiography. C- Sagittal midline CT scan with a narrow L5S1 disc space. D) Sagittal midline T2 sequence MRI. E) Lateral lumbar spine after an anterior lumbar interbody fusion was performed at $L 45$ followed by posterior $L 4$ pedicle and L5S1 transdiscal screws fixation. F- Postoperative antero-posterior simple plain radiography, $\mathrm{G}$ - sagittal midline $\mathrm{CT}$ and $\mathrm{H}$ - parasagittal $\mathrm{CT}$ in the level of the transdiscal screw fixation. The patient had a good clinical improvement after surgery.

lolisthesis ${ }^{19}$. Despite high grades of slippage, patients may be totally asymptomatic, and surgical indication may be accepted when progression is documented on serial radiological exams ${ }^{12,14,20}$. Reduction is proposed to decrease pseudoarthrosis rate, as interbody devices provide a large area of endplate surface for fusion ${ }^{15}$. Potential advantages of performing a slip reduction are to correct the slip angle and also restore the normal or near normal spino-pelvic relationships, which may avoid sagittal balance problems. However, in our review, none of the studies addressed comparatively spino-pelvic measurements for such anal- ysis. On the other hand, neurological deficits, such as permanent L5 radiculopathy, were described in patients who underwent circumferential fusion with reduction of $\mathrm{HGLS}^{20}$. None of the patients evaluated in our review who had a PTD had permanent radicular deficits. For this reason, the evaluation of all the different techniques used for the treatment of this relatively rare and complex entity is necessary.

We reported the clinical and radiological outcome of the studies that had patients with HGLS treated with PTD screw fixation. As general conclusions, most of the studies reported that patients improved clinically 
after surgery, had the intensity of their pain decreased and had no additional neurological deficits with low surgical revision rates. Many surgeons reported that in situ fusion for HGLS had less risk of L5 nerve root injuries and also better long-term outcomes ${ }^{4,21-23}$.

Considering both the large series evaluated in our review, PTD is technically more demanding due to screw trajectory than traditional pedicle screw fixation. However, it is potentially more efficient and less technically demanding than a TLIF (less surgical time, less durotomies), with similar clinical outcomes $^{13,17}$.

Potential advantages are the triangular screw-toscrew secondary to the anteromedial direction of the screws through the sacral promontory, resulting in higher construction strength because of the mass of bone between the hardware instead of the amount of bone purchased by standard pedicle screw fixation ${ }^{24}$. Minamide et al. ${ }^{25}$ performed a biomechanical analysis in cadaver models, whereas the construction using PTD were 1.6 to 1.8 times stiffer than conventional pedicle screw fixation.

In two case reports included in our review, authors reported an additional anterior approach combined with PTD. In the case of Beringer et al. ${ }^{12}$, a L45 ALIF and a transvertebral anterior cage from L5S1 were performed for additional support in a 34-years-old patient. In the Jo et al. ${ }^{18}$ case, authors performed also iliac screw fixation posteriorly, as well as a more cranial construction (L2, 3 and 4 fixation) followed by an L34 and 45 ALIF and an additional anterior screw from L5 to S1. Although additional anterior fixation may not be routinely necessary, it may be interesting in cases such as those presented by Jo et al. ${ }^{18}$, who had a severe osteoporosis. The additional anterior support may have its rationale derived from the Bohlman technique, which a circumferential fusion was performed by a posterior only approach using a fibular graft for interbody fusion, which is inserted transsacral towards the L5 body ${ }^{8}$.

Finally, an important limitation of our review is that the majority of the cases included did not evaluate the role of global spinal alignment and spino-pelvic relationships in their surgical planning. Further studies about transdiscal screw fixation should evaluate the spino-pelvic relationships in the outcome of high-grade spondylolisthesis management.

\section{CONCLUSIONS}

Our review concludes, with limited evidence that PTD fixation is a safe and effective technique for treating HGLS patients. It is technically less demanding that a circumferential fusion, even though proper screw insertion is more demanding than conventional pedicle screw fixation. The superiority of this technique over others for the treatment of HGLS still needs to be proven.

\section{Conflict of interests}

No funds were received in support of this study. No benefits in any form have been or will be received from a commercial party related directly or indirectly to the subject of this manuscript. The authors have no financial interest in the subject of this article. The manuscript submitted does not contain information about medical device(s).

\section{RESUMO}

OBJETIVOS: O tratamento cirúrgico das listeses de alto grau da coluna lombar (LAGCL) é complexo, objetivando alcançar uma fusão sólida capaz de suportar o estresse biomecânico da junção lombo-sacra, bem como descompressão do tecido neural. Realizamos revisão sistemática da literatura para avaliar a segurança e a eficácia da fixação transdiscal (FTD) L5S1 em LAGCL e suas variações.

MÉTOdos: Realizamos revisão sistemática conforme metodologia Prisma na base de dados PubMed dos estudos que utilizaram FTD no tratamento das LAGCL e suas variações. Dados clínicos e radiológicos foram extraídos dos trabalhos e discutidos. A qualidade dos estudos foi avaliada segundo o Oxford Centre for Evidence-Based Medicine Levels of Evidence.

RESULTADOS: Sete estudos foram incluídos e analisados, todos com nível IV de evidência. Dois estudos tinham séries de casos maiores, comparando diferentes técnicas cirúrgicas: um concluiu que a FTD foi associada a melhor prognóstico clínico quando comparada à fixação pedicular tradicional, e o outro sugeriu que os resultados clínicos e radiológicos com a FTD foram semelhantes à fusão intersomática, porém com menor demanda técnica na FTD. Os demais cinco estudos eram pequenas séries ou relatos de casos. Todos reportaram o uso da FTD com sucesso, com e sem variações da técnica.

CONCLUSÃo: Concluímos que, embora com evidências limitadas, a FTD é segura e efetiva no tratamento das LAGCL. É tecnicamente mais simples do que a fusão circunferencial (intersomática), porém com maior complexidade que a fixação pedicular convencional.

PALAVRAS-CHAVE: Espondilolistese. Espondilólise. Vértebras lombares/cirurgia. Revisão 


\section{REFERENCES}

1. Meyerding HW. Spondylolisthesis: surgical treatment and results. Surg Gynecol Obstet. 1932/54:371-7.

2. Ani N, Keppler L, Biscup RS, Steffee AD. Reduction of high-grade slips (grades III-V) with VSP instrumentation. Report of a series of 41 cases. Spine (Phila Pa 1976). 1991;16(6 Suppl):S302-10.

3. Kasliwal MK, Smith (S, Kanter A, Chen C), Mummaneni PV, Hart RA, et al. Management of high-grade spondylolisthesis. Neurosurg Clin N Am. 2013;24(2):275-91.

4. Lamberg T, Remes V, Helenius I, Schlenzka D, Seitsalo S, Poussa M. Uninstrumented in situ fusion for high-grade childhood and adolescent isthmic spondylolisthesis: long-term outcome. J Bone Joint Surg Am. 2007;89(3):512-8.

5. Roca J, Ubierna MT, Cáceres E, Iborra M. One-stage decompression and posterolateral and interbody fusion for severe spondylolisthesis. An analysis of 14 patients. Spine (Phila Pa 1976). 1994,24(7):709-14.

6. Gill GG, Manning JG, White HL. Surgical treatment of spondylolisthesis without spine fusion: excision of the loose lamina with decompression of the nerve roots. J Bone Joint Surg Br. 1955;37-A(3):493-520.

7. König MA, Boszczyk BM. Limited access surgery for 360 degrees in-situ fusion in a dysraphic patient with high-grade spondylolisthesis. Eur Spine J. 2012;21(3):390-5.

8. Bohlman HH, Cook SS. One-stage decompression and posterolateral and interbody fusion for lumbosacral spondyloptosis through a posterior approach. Report of two cases. J Bone Joint Surg Am. 1982;64(3):415-8.

9. Abdu WA, Wilber RG, Emery SE. Pedicular transvertebral screw fixation of the lumbosacral spine in spondylolisthesis. A new technique for stabilization. Spine (Phila Pa 1976). 1994;19(6):710-5.

10. Moher D, Liberati A, Tetzlaff J, Altman DG; PRISMA Group. Preferred reporting items for systematic reviews and meta-analyses: the PRISMA statement. Int J Surg. 2010;8(5):336-41.

11. Oxford Centre for Evidence-Based Medicine Levels of Evidence. [cited 2015 Oct 16]. Available from: http://www.cebm.net/index.aspx?o=5653

12. Beringer WF, Mobasser JP, Karahalios D, Potts EA. Anterior transvertebral interbody cage with posterior transdiscal pedicle screw instrumentation for high-grade spondylolisthesis. Technical note. Neurosurg Focus. 2006;20(3):E7.

13. Collados-Maestre I, Lizaur-Utrilla A, Bas-Hermida T, Pastor-Fernandez E, Gil-Guillen V. Transdiscal screw versus pedicle screw fixation for highgrade L5-S1 isthmic spondylolisthesis in patients younger than 60 years: a case-control study. Eur Spine J. 2016;25(6):1806-12.
14. François J, Lauweryns P, Fabry G. Treatment of high-grade spondylolisthesis by posterior lumbosacral transfixation with transdiscal screws: surgical technique and preliminary results in four cases. Acta Orthop Belg. 2005;71(3):334-41.

15. Palejwala A, Fridley J, Jea A. Transsacral transdiscal L5-S1 screws for the management of high-grade spondylolisthesis in an adolescent. J Neurosurg Pediatr. 2016;17(6):645-50.

16. Pasha IF, Qureshi MA, Haider IZ, Malik AS, Qureshi MA, Bin Tahir U. Surgical treatment in lumbar spondylolisthesis: experience with 45 patients. ) Ayub Med Coll Abbottabad. 2012;24(1):75-8.

17. Rodriguez-Olaverri JC, Zimick NC, Merola A, Vicente J, Rodriguez J, Tabuenca A, et al. Comparing the clinical and radiological outcomes of pedicular transvertebral screw fixation of the lumbosacral spine in spondylolisthesis versus unilateral transforaminal lumbar interbody fusion (TLIF) with posterior fixation using anterior cages. Spine (Phila Pa 1976). 2008;33(18):1977-81.

18. Jo DJ, Seo EM, Kim KT, Kim SM, Lee SH. Lumbosacral spondyloptosis treated using partial reduction and pedicular transvertebral screw fixation in an osteoporotic elderly patient. J Neurosurg Spine. 2012;16(2):206-9.

19. Saraste $H$. Long-term clinical and radiological follow-up of spondylolysis and spondylolisthesis. J Pediatr Orthop. 1987;7(6):631-8.

20. Bouyer B, Bachy M, Courvoisier A, Dromzee E, Mary P, Vialle R. Highgrade lumbosacral spondylolisthesis reduction and fusion in children using transsacral rod fixation. Childs Nerv Syst. 2014;30(3):505-13.

21. Lamartina C. Posterior instrumentation, reduction and fusion in spondyloptosis. Eur Spine J. 2010;19(10):1799-800.

22. Poussa M, Remes V, Lamberg T, Tervahartiala P, Schlenzka D, Yrjönen T, et al. Treatment of severe spondylolisthesis in adolescence with reduction or fusion in situ: long-term clinical, radiologic, and functional outcome. Spine (Phila Pa 1976). 2006;31(5):583-90.

23. Transfeldt EE, Mehbod AA. Evidence-based medicine analysis of isthmic spondylolisthesis treatment including reduction versus fusion in situ for high-grade slips. Spine (Phila Pa 1976). 2007;32(19 Suppl):S126--9.

24. Ruland CM, McAfee PC, Warden KE, Cunningham BW. Triangulation of pedicular instrumentation. A biomechanical analysis. Spine (Phila Pa 1976). 1991;16(6 Suppl):S270-6.

25. Minamide A, Akamaru T, Yoon ST, Tamaki T, Rhee JM, Hutton WC. Transdiscal L5-S1 screws for the fixation of isthmic spondylolisthesis: a biomechanical evaluation. J Spinal Disord Tech. 2003;16(2):144-9. 